
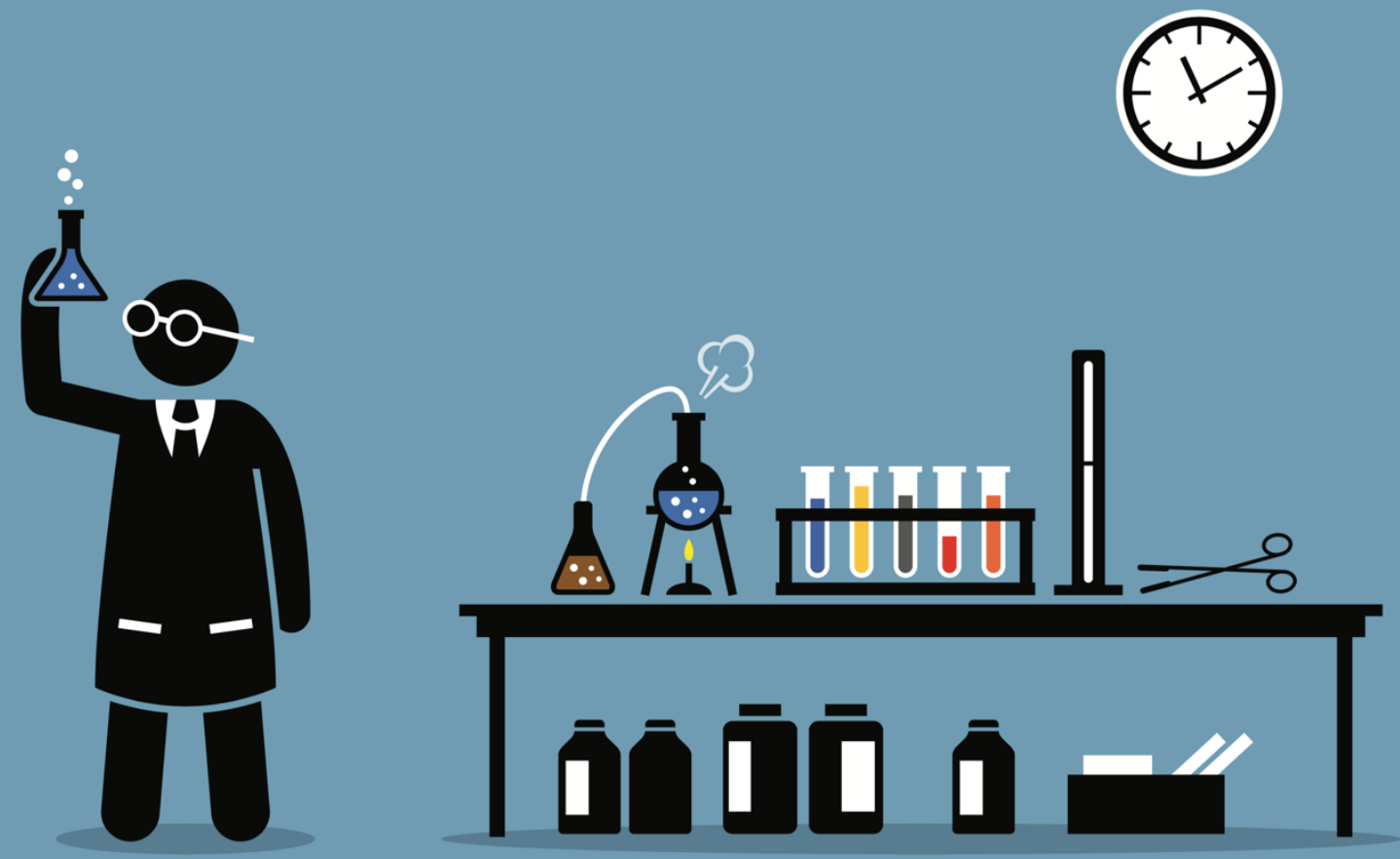

\title{
Editorial
}

\section{Clinical trial transparency}

Richeek Pradhan, MD, MS, Ph.D. (c) ${ }^{1,2}$, Olivia Bonardi ${ }^{2}$ MJM 2019 17(11)

Sharing the results of clinical research conducted on human participants is the researcher's ethical imperative. While publishing research papers in medical journals is one way to do so, this limits the accessibility of the results to the select few who read such journals, effectively hiding the results from general public awareness, veiled in medical jargon and behind journals' paywalls. Importantly also, publishing results in journals is ultimately the researcher's prerogative, which means that results of research that are negative or unfavorable often remain unpublished. Indeed, half the trials conducted are never published in journals and negative results are less likely to be published in journals (1).
Another way that transparency in sharing research results can be achieved is reporting summary results in open-access clinical trial registries (2-4). Besides making the research more transparent and results more accessible to the general public, trial reports in such registries have been thought to form a storehouse of negative results that are otherwise not published in journals (5). Indeed, trial registries are considered a resource indispensable to achieve balanced medical evidence synthesis that informs clinical decisionmaking, and their use in systematic reviews has been associated with reduced publication bias (6). In fact, the Declaration of Helsinki, World Medical Association's prescribed standards of human experimentation, instructs researchers to make

\footnotetext{
${ }^{1}$ Department of Epidemiology, Biostatistics, and Occupational Health, McGill University, Montréal, Canada.

${ }^{2}$ Clinical Trial Transparency Committee, Universities Allied for Essential Medicine, McGill Chapter

Corresponding Author: Richeek Pradhan, richeek.pradhan@mail.mcgill.ca.
} 
negative, inconclusive as well as positive results publicly available (2). Similarly, the US Food and Drug Administration and the European Medical Agency mandate reporting of clinical trial results in their respective registries (ClinicalTrials.gov and EudraCT) within 12 months of ending of the trial, irrespective of whether the researcher chooses to publish the results in journals or not. Health Canada, despite not having its own trial registry, encourages registering of trials in ClinicalTrials.gov (7). Moreover, in federally funded institutes, public reporting of results is mandatory as per the research ethics standard of the federal funding agencies $(8,9)$.

So, how do Canadian institutions fare at reporting trial results in open access trial registries or journals? TrialsTracker (10), is a tool created to check trial underreporting. Among the studies registered in ClinicalTrials.gov where McGill University Health Center was a sponsor or a collaborator, $59 \%$ do not have their results reported in either journals or ClinicalTrials.gov (11). Other Canadian universities have a similarly poor performance with McMaster University at $46 \%$ of unreported studies, University of Toronto at $64 \%$ and University of British Columbia at $74 \%$ (11). Following TrialsTracker's methodology, an updated manual search conducted using ClinicalTrials.gov showed that among the interventional studies completed before December 2017 McGill University Health Center was the lead sponsor, results remained unpublished in journals for 37\% and unreported in ClinicalTrials.gov for 91\% (12).

But the situation does not have to be like this. For example, all major British universities, held accountable by funding agencies, public pressure, and legal mandates, have reporting rates of more than $90 \%$ (13). Interestingly, pharmaceutical companies sponsoring research also have a high degree of compliance in reporting trial results in a timely manner (14). This shows that, with the right push, the situation can improve. In fact, Health Canada's recent move to publish in its website results of studies used to seek regulatory marketing approval for drugs and medical devices signals a change in attitude towards trial data transparency (15). However, since only a fraction of all clinical studies recruiting human participants is used to seek regulatory approvals, this move addresses the mere tip of the iceberg in the campaign to fight obfuscation of trial results, and in no manner reduces the need to report results in trial registries.

More needs to be done to ensure transparency is achieved in the dangerous yet critically important undertaking of clinical experimentation with human life. And doing so requires concerted effort from all stakeholders in the clinical trial enterprise. At the forefront must remain the researcher, who bears the primary responsibility to disclose summary results to publicly available databases. Yet not far behind can remain the members of the hospital ethics boards overseeing the clinical trials, research committees, funding agencies, regulators, and the general public, all of whose duty it is to ensure that science is being pursued at the universities with a commitment towards transparency, and the results, good, bad, or neutral, are accessible to all.

\section{About the Authors}

The authors are members of Universities Allied for Essential Medicines-McGill chapter, UAEM_McGill, a student organization committed to bringing about positive change in research practices. They are initiating a campaign to improve registry-reporting rates of studies with human participants conducted at McGill University research centers. They plan to actively engage with research ethics committees and researchers to ensure that the result reporting rates rise, the backlog of unreported studies is cleared, and that the university establishes a sustainable mechanism that maintains high reporting rates in the future.

\section{References}

1. F. Song, S. Parekh, L. Hooper, Y.K. Loke, J. Ryder, A.J. Sutton, C. Hing, C.S. Kwok, C. Pang, I. Harvey, Dissemination and publication of research findings: an updated review of related biases, Health Technol. Assess. Winch. Engl. 14 (2010) iii, ix-xi, 1-193. doi:10.3310/hta14080.

2. $\mathrm{WHO} \mid$ Joint statement on public disclosure of results from clinical trials, WHO. (n.d.). http://www.who.int/ictrp/results/jointstatement/en/ (accessed June 20, 2019).

3. Why Should I Register and Submit Results? ClinicalTrials.gov, (n.d.). https://clinicaltrials.gov/ct2/manage-recs/background (accessed June 20, 2019).

4. T. Tse, R.J. Williams, D.A. Zarin, Reporting "basic results" in ClinicalTrials.gov, Chest. 136 (2009) 295303. doi:10.1378/chest.08-3022.

5. Trial registries and publication bias, Cochrane Handb. (n.d.). https://handbook-5-

1.cochrane.org/chapter_10/10_3_3_trial_registries_an d_publication_bias.htmhttps://handbook-5-

1.cochrane.org/chapter_10/10_3_3_trial_registries_an d_publication_bias.htm.

6. R. Pradhan, K. Garnick, B. Barkondaj, H.S. Jordan, A. Ash, H. Yu, Inadequate diversity of information resources searched in USA-affiliated systematic 
reviews and meta-analyses: 2005-2016, J. Clin.

Epidemiol. (2018). doi:10.1016/j.jclinepi.2018.05.024.

7. H. Canada, Health Canada's Clinical Trials Database, Aem. (2013). https://www.canada.ca/en/healthcanada/services/drugs-health-products/drugproducts/health-canada-clinical-trials-database.html (accessed June 25, 2019).

8. T. Lemmens, C.H. Vacaflor, Clinical trial transparency in the Americas: the need to coordinate regulatory spheres, BMJ. 362 (2018) k2493.

doi:10.1136/bmj.k2493.

9. I.A.P. on R.E. Government of Canada, Interagency Advisory Panel on Research Ethics, (2016). http://www.pre.ethics.gc.ca/eng/policypolitique/initiatives/tcps2-eptc2/Default/ (accessed June 25, 2019).

10. A. Powell-Smith, B. Goldacre, The TrialsTracker: Automated ongoing monitoring of failure to share clinical trial results by all major companies and research institutions, F1000Research. 5 (2016) 2629. doi:10.12688/f1000research.10010.1.

11. Who's not sharing their trial results?, TrialsTracker. (n.d.). https://trialstracker.ebmdatalab.net/\#/.

12. R. Pradhan.Tracking-clinical-trial-reporting-byCanadian-universities development by creating an account on GitHub, 2019.

https://github.com/RicheekPradhan/Tracking-clinicaltrial-reporting-by-Canadian-universities (accessed June 25, 2019).

13. T. Bruckner, Why British universities are now racing to post their clinical trial results, TranspariMed. (n.d.). https://www.transparimed.org/singlepost/2019/04/09/British-universities-are-racing-topost-their-clinical-trial-results.

14. A.P. Prayle, M.N. Hurley, A.R. Smyth, Compliance with mandatory reporting of clinical trial results on ClinicalTrials.gov: cross sectional study, BMJ. 344 (2012) d7373. doi:10.1136/bmj.d7373.

15. J. Lexchin, M. Herder, P. Doshi, Canada finally opens up data on new drugs and devices, BMJ. 365 (2019) |1825. doi:10.1136/bmj.|1825. 